\title{
Genetic variation, heritability, divergence and biomass accumulation of rice genotypes resistant to bacterial blight revealed by quantitative traits and ISSR markers
}

\begin{abstract}
A field experiment was carried out in order to evaluate genetic diversity of 41 rice genotypes using physiological traits and molecular markers. All the genotypes unveiled variations for crop growth rate (CGR), relative growth rate (RGR), net assimilation rate (NAR), yield per hill (Yhill-1), total dry matter (TDM), harvest index (HI), photosynthetic rate (PR), leaf area index (LAI), chlorophyll-a and chlorophyll-b at maximum tillering stage. The CGR values varied from 0.23 to $0.76 \mathrm{gm} \mathrm{cm}-2$ day -1 . The Yhill-1 ranged from 15.91 to $92.26 \mathrm{~g}$, while TDM value was in the range of 7.49 to $20.45 \mathrm{~g}$ hill-1. PR was found to vary from 9.40 to $22.34 \mu \mathrm{mol} \mathrm{m}-2 \mathrm{~s}-1$. PR expressed positive relation with Yhill-1. Significant positive relation was found between CGR and TDM $(\mathrm{r}=0.61 * *)$, NAR and CGR $(\mathrm{r}=0.62 * *)$ and between TDM and NAR $\left(r=0.31^{* *}\right)$. High heritability was found in RGR and Yhill-1. Cluster analysis based on the traits grouped 41 rice genotypes into seven clusters. A total of 310 polymorphic loci were detected across the 20 inter-simple sequence repeats (ISSR) markers. The UPGMA dendrogram grouped 41 rice genotypes into 11 clusters including several sub-clusters. The Mantel test revealed positive correlation between quantitative traits and molecular markers $(r=0.41)$. On the basis of quantitative traits and molecular marker analyses parental genotypes, IRBB54 with MR84, IRBB60 with MR84, Purbachi with MR263, IRBB65 with BR29, IRBB65 with Pulut Siding and MRQ74 with Purbachi could be hybridized for future breeding program.
\end{abstract}

Keyword: Rice genotypes; Quantitative trait; Genetic diversity 